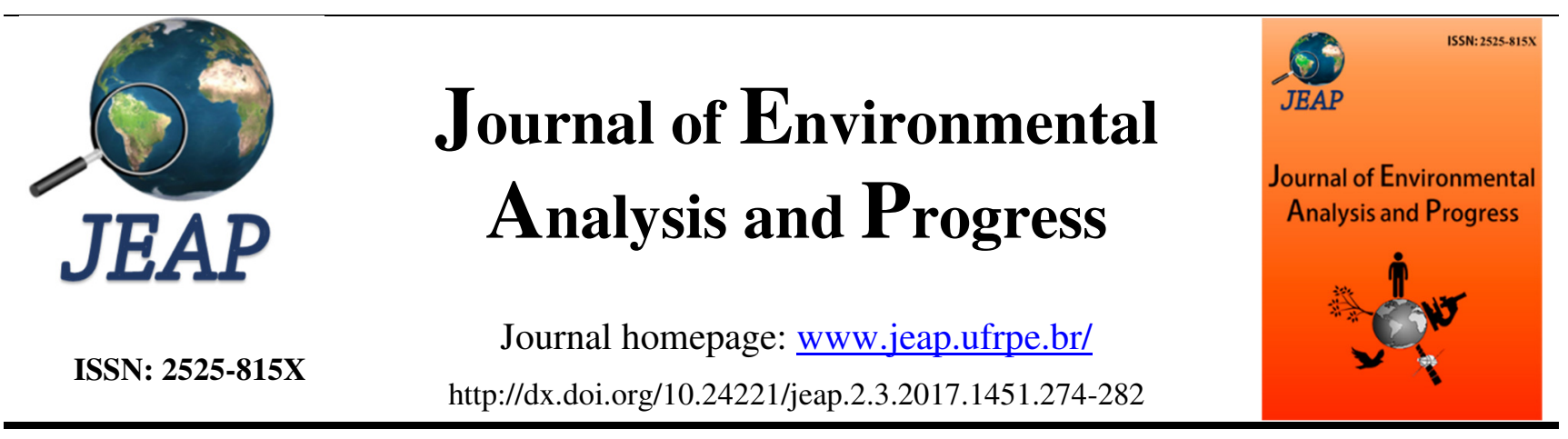

\title{
Características agronômicas e sensibilidade ao rachamento de bagas de uvas sem sementes
}

\section{Agronomic characteristics and sensitivity to berries cracking of seedless grape}

Leide Dayane da Silva Oliveira ${ }^{a}$, Magna Soelma Beserra de Moura ${ }^{a}$, Patrícia Coelho de Souza Leão $^{\mathrm{a}}$, Thieres George Freire da Silva ${ }^{\mathrm{b}}$, Luciana Sandra Bastos de Souza ${ }^{\mathrm{b}}$

a Embrapa Semiárido. BR 428, Km 152, Caixa Postal 23, Zona Rural, Petrolina, Pernambuco, Brasil. CEP: $56302-970$. E-mail: leidedayane.bio@gmail.com; magna.moura@embrapa.br; patricia.leao@embrapa.br.

${ }^{\mathrm{b}}$ Universidade Federal Rural de Pernambuco, UFRPE/UAST. Avenida Gregório Ferraz Nogueira, S/N. Bairro: José Tomé de Souza Ramos, Serra Talhada, Pernambuco, Brasil. CEP: 56909-535. E-mail: thieres_freire@yahoo.com.br; sanddrabastos@gmail.com.

\begin{tabular}{l}
\hline A R T I C L E I N F O \\
\hline Recebido 29 Jun 2017 \\
Aceito 10 Jul 2017 \\
Publicado 31 Jul 2017
\end{tabular}

\begin{abstract}
A B S T R A C T
The varieties of seedless grapes are harder to adapt to the tropical conditions of the northeastern semi-arid region, exhibiting reduced and irregular yields, as a result of their low yolk fertility, the high pill and susceptibility to cracking berries. The objective of this study was to evaluate aspects related to the susceptibility to cracking and rot of berries and agronomic characteristics of seedless grapes under the conditions of the Low-Middle São Francisco River Valley. The field experiment carried out in the Bebedouro Experimental Field at Embrapa Tropical Semiarid, in Petrolina Municipality, Pernambuco State, Brazil. Five seedless grape varieties were evaluated over two production cycles (2013 and 2014 years). 'BRS Clara', 'BRS Maria Bonita', 'Arizul' and 'Thompson Seedless' varieties were evaluated for productivity $\left(\mathrm{kg}_{\text {. }}\right.$ plant $\left.^{-1}\right)$, number of bunches, cluster mass $(\mathrm{g})$; soluble solids content ( ${ }^{\circ}$ Brix) and titratable acidity (tartaric acid); cracked berries (\%) and rotten berries (\%). The percentage of cracking, as the rot, showed that the 'BRS Clara' and 'Adona' varieties as the most resistant, and 'Thompson' variety as the most susceptible to those parameters. The highest productivity was obtained in Cycle 2 for 'BRS Clara' variety (20.63 kg.plant ${ }^{-1}$ ), followed by 'Adona' (17.52 kg.plant ${ }^{-1}$ ). Thus, 'BRS Clara' and 'Adona' varieties stood out with better quality characteristics and greater resistance to berries cracking and rot, presenting the potential for production area expansion in the Low-middle São Francisco River Valley.
\end{abstract}

Keywords: Vitis vinifera, precipitation, production.

\section{R E S U M O}

As variedades de uvas sem sementes apresentam maior dificuldades de adaptação às condições tropicais do semiárido nordestino, exibindo produções reduzidas e irregulares, resultado de sua baixa fertilidade de gemas, desgrane elevado e suscetibilidade à rachadura de bagas. $\mathrm{O}$ objetivo deste estudo foi avaliar aspectos relacionados à susceptibilidade ao rachamento e podridão de bagas e características agronômicas de uvas sem sementes sob as condições do Submédio do Vale São Francisco. O experimento foi conduzido no Campo Experimental de Bebedouro na Embrapa Semiárido, em Petrolina-PE. Foram avaliadas cinco variedades ao longo de dois ciclos de produção, correspondendo aos anos de 2013 e 2014. Utilizaram-se as variedades Adona, BRS Clara, BRS Maria Bonita, Arizul e Thompson Seedless, nas quais foram determinadas as seguintes variáveis: produção (kg.planta ${ }^{-1}$ ), 
número de cachos, massa do cacho $(\mathrm{g})$; teor de sólidos solúveis ( ${ }^{\circ}$ Brix) e acidez titulável (ácido tartárico); bagas rachadas (\%) e bagas podres (\%). O percentual de rachamento, tanto quanto o de podridão, apontaram para as variedades BRS Clara e Adona como as mais tolerantes e a variedade Thompson Seedless como a mais suscetível. A maior produção por planta foi obtida no Ciclo 2 para a variedade BRS Clara (20,63 kg.planta $\left.{ }^{-1}\right)$, seguida da Adona (17,52 kg.planta $\left.{ }^{-1}\right)$. As variedades BRS clara e Adona destacaram-se com melhores características de qualidade e maior tolerância à rachadura e podridões de bagas, apresentando potencial para produção de duas safras ao ano no Submédio do Vale São Francisco.

Palavras-Chave: Vitis vinifera, precipitação, produção.

\section{Introdução}

A uva é uma das principais frutas comercializadas no Brasil. Em 2015, a produção total de frutos foi de 1.505.654 toneladas, em uma área de 79.017 ha plantados (Agrianual, 2016). No Nordeste, nas cidades de Petrolina-PE/JuazeiroBA, região do Vale do Submédio São Francisco, há aproximadamente 9.621 ha produzindo em torno de 315.338 toneladas de uvas (Agrianual, 2016).

No entanto, em geral, as variedades de uvas sem sementes apresentam maior dificuldades de adaptação às condições tropicais do semiárido nordestino, exigindo a adoção de maior quantidade de técnicas de manejo, exibindo produções reduzidas e irregulares, resultado de sua baixa fertilidade de gemas, desgrane elevado e suscetibilidade à rachadura de bagas em condições de chuva durante a fase de maturação, além de elevada incidência de podridões, causando grandes prejuízos aos viticultores desta região (Leão, 2002). Segundo Mello (2009), chuvas acima da média durante a colheita provocaram perdas de até $40 \%$ em uvas de mesa na região do Vale do São Francisco. Esse problema vem sendo estudado sob diferentes perspectivas, como associados aos fatores ambientais, fisiológicos e genéticos, uma vez que comumente são verificadas diferenças entre as cultivares de uva quanto à suscetibilidade à rachadura da baga (Lang \& Düring, 1990). Há alguns anos, os produtores tentaram reduzir os impactos da chuva na época da colheita da videira utilizando-se de barreiras físicas e mecânicas, como filmes de polietileno sobre os parreirais (Moura et al., 2006). Entretanto, apesar da redução dos índices de rachadura, não há garantias de controle do problema e os custos envolvidos são elevados (Balbotin et al., 2013).

Existem poucos estudos sobre a determinação da sensibilidade à rachadura da baga das principais cultivares de uva para processamento produzidas no Brasil (Yamamoto \& Satoh, 1994; Fava et al., 2011). Estudos dessa natureza poderão auxiliar na seleção e indicação de cultivares tolerantes e contribuir para a definição das áreas de cultivo mais adequadas, reduzindo os riscos de perdas. Assim, o objetivo deste estudo foi avaliar aspectos relacionados à sensibilidade à rachadura e à podridão de bagas, associados a características agronômicas de cinco variedades de uvas sem sementes sob as condições do Submédio do Vale São Francisco.

\section{Material e Métodos}

$\mathrm{O}$ experimento foi conduzido no Campo Experimental de Bebedouro (909' S, 40²2' O e $365,5 \mathrm{~m})$, pertencente à Embrapa Semiárido, localizado no município de Petrolina-PE. O clima da região segundo a classificação de Köppen é do tipo BSwh', ou seja, semiárido com temperaturas médias anuais elevadas, da ordem de $26^{\circ} \mathrm{C}$, e precipitação média de 503,08 $\mathrm{mm}$ (Embrapa Semiárido, 2017). O solo da área de estudo foi descrito como Argissolo Vermelho Eutrófico abrúptico plintossólico A moderado, com textura média fase caatinga hiperxerófila relevo plano.

$O$ parreiral no qual se realizou $O$ experimento foi composto de cinco variedades de uvas sem sementes, selecionadas no Banco Ativo de Germoplasma (BAG) da Embrapa Semiárido: Adona, BRS Clara, BRS Maria Bonita, Arizul e Thompson Seedless, sendo esta última considerada a Testemunha por ser sensível a rachadura e cultivada pelos produtores. As plantas foram conduzidas no sistema de latada, no espaçamento de $3 \mathrm{~m}$ entre linhas por $2 \mathrm{~m}$ entre plantas, e enxertadas no porta-enxerto Paulsen 1103 (P1103). O sistema de irrigação utilizado foi do tipo gotejamento. O manejo da copa compreendeu operações de poda seca, amarrio de ramos, desbrota, desfolha, desponte dos ramos e raleio de bagas. As adubações e tratamentos fitossanitários foram realizados de acordo com as recomendações para a cultura da videira nesta região (Soares \& Leão, 2009).

$\mathrm{O}$ delineamento experimental foi em blocos ao acaso com quatro repetições em parcelas subdivididas, onde as parcelas principais foram representadas por quatro datas de poda (D1, D2, D3 e D4) e as parcelas secundárias por cinco variedades de uvas sem sementes. Para este estudo, foram avaliados os ciclos produtivos dos anos 2013 e 2014. Para a determinação das datas de poda foi realizado um estudo de probabilidade de ocorrência de chuvas semanais superiores a 10 
$\mathrm{mm}$ em Petrolina, PE, realizando-se as podas nas seguintes datas: D1-2013: 03/09/2013, D1-2014: 06/08/2014; D2-2013: 17/09/2013, D2-2014: 01/09/2014; D3-2013: 01/10/2013, D3-2014: 06/10/2014; D4-2013: 15/10/2013 e D4-2014: 03/11/2014.

Em cada data de poda foram determinados a duração do ciclo expresso em número de dias após a poda (DAP) e a exigência térmica em graus-dia acumulados (GDA). Os GDA, foram calculados assumindo a temperatura base de $10^{\circ} \mathrm{C}$ e a Equação 1, proposta por Ometto (1981):

$\mathrm{GDA}=\sum t m-t b$

onde $t_{\mathrm{m}}=$ temperatura média $\mathrm{e}_{\mathrm{b}}=$ temperatura base.

Para o monitoramento das condições microclimáticas do parreiral foram instalados sensores eletrônicos no centro da área em estudo. Esses sensores foram conectados a um sistema automático de aquisição de dados datalogger (modelo CR800X, Campbell Scientific INC, Logan, Utah, USA), programado para realizar leituras a cada cinco segundos e armazenar médias de trinta minutos dos seguintes elementos meteorológicos: temperatura do ar (Tar), umidade relativa do ar (Ur), e velocidade do vento (Vv). Os dados da radiação solar incidente $(\mathrm{Rg}) \mathrm{e}$ precipitação (P) foram obtidos da Estação Agrometeorológica de Bebedouro, localizada a cerca de $130 \mathrm{~m}$ da área de estudo.

No momento da colheita, foi determinada a produção pela soma total do peso de todos os cachos da planta (kg.planta ${ }^{-1}$ ), em três plantas por parcela.

Para a determinação das características físico químicas das uvas, foram colhidos cinco cachos, aleatoriamente, em quatro plantas da parcela útil, totalizando vinte cachos para determinação das seguintes variáveis: massa do cacho (g); teor de sólidos solúveis ( ${ }^{\circ}$ Brix) e acidez titulável (g ácido tartárico por $100 \mathrm{~mL}$ ); bagas rachadas (\%) e bagas podres (\%). A avaliação da massa dos cachos foi feita por pesagens individuais em balança eletrônica.

As análises do teor de sólidos solúveis (SS) e acidez titulável (AT) foram realizadas após a colheita dos frutos no laboratório de Fisiologia Pós-colheita da Embrapa Semiárido. Utilizou-se como amostra o suco extraído de cinquenta bagas por planta. Tomou-se uma gota deste suco para leitura do teor de sólidos solúveis ( ${ }^{\circ}$ Brix) em refratômetro digital Abbe Marck II (Reichert Jung, Depew, NY, EUA) (AOAC, 1995). A acidez titulável foi determinada por titulação com solução de $\mathrm{NaOH} 0,1 \mathrm{~N}$, tendo como indicador a fenolftaleína $0,1 \%$, expressando-se os resultados em gramas de ácido tartárico.100 $\mathrm{mL}^{-1}$ (AOAC, 1995). A incidência de podridões e de rachamento foram analisadas por contagem do número de bagas com estes problemas, transformando-se os valores em porcentagem.

As análises estatísticas foram realizadas utilizando o software XLSTAT, os dados foram submetidos ao teste de normalidade, no entanto, algumas variáveis apresentaram distribuição não normal, sendo avaliadas separadamente por meio da análise não paramétrica pelo teste de KruskalWallis ${ }^{1}$ e médias comparadas pelo teste de Dunn ${ }^{1}$ a 5\% de significância. As variáveis com distribuição normal foram analisadas pela ANOVA $^{2}$ e médias comparadas pelo teste de Tukey $^{2}$ a $5 \%$ de significância.

\section{Resultados}

Na Figura 1 é apresentada a sazonalidade dos parâmetros climáticos médios diários durante os dois ciclos produtivos estudados. Pode-se constatar que ambos os ciclos de produção foram conduzidos em um período com temperatura do ar mais elevada, que ocorrem entre os meses de outubro e janeiro. A temperatura média do ar, durante o primeiro ciclo, variou entre $23,78^{\circ} \mathrm{C}$ e $30,34^{\circ} \mathrm{C}$ (Figura 1a), enquanto no segundo ciclo oscilou entre $22,66^{\circ} \mathrm{C}$ e $31,52^{\circ} \mathrm{C}$ (Figura 1e).

Da mesma forma, a umidade relativa do ar média durante o experimento é apresentada na Figura $1(\mathrm{a}, \mathrm{e})$ onde se verificou em ambos os ciclos umidade máxima próxima aos $100 \%$ quando ocorreram eventos de precipitação; e mínimo inferior a $40 \%$, com média ao redor de $59 \%$. A radiação solar média atingiu valores em torno de $18,14 \mathrm{MJ} \cdot \mathrm{m}^{-2} \cdot \mathrm{dia}^{-1}$ e $16,86 \mathrm{MJ} \cdot \mathrm{m}^{-2} \cdot \mathrm{dia}^{-1}$, para o Ciclo 1 e Ciclo 2, respectivamente, enquanto em alguns dias verificaram-se valores mínimos da ordem de 5,77 MJ.m ${ }^{-2} \cdot \operatorname{dia}^{-1}$ e 3,52 MJ.m ${ }^{-2} \cdot$ dia $^{-1}$ e máximos 30,20 MJ.m. ${ }^{-2} \cdot \operatorname{dia}^{-1}$ e 26,79 MJ.m ${ }^{-2}$.dia ${ }^{-1}$ (Figura 1bf), mostrando a ocorrência tanto de dias com bastante nebulosidade, quanto dias de céu claro, sendo que a maior parte dos ciclos ocorreu em dias com $\mathrm{Rg}$ entre 15 e 20 MJ.m2.dia ${ }^{-1}$. A velocidade do vento se reduz por ocasião da precipitação e com o desenvolvimento da videira, tendo sido em média igual a $1,54 \mathrm{~m} \cdot \mathrm{s}^{-1}$ e 2,65 m.s ${ }^{-1}$, respectivamente para os Ciclos 1 e 2 (Figura 1cg).

Observa-se que a maior parte das chuvas ocorreram entre 04/11/2013 e 21/12/2013 e 16/11/2014 e 19/12/2014, respectivamente, nos Ciclos 1 e 2 (Figura 1dh); posteriormente, no segundo ciclo avaliado, voltou a ocorrer uma sequência de dias com chuva nos meses de fevereiro e março de 2015. Durante os 
experimentos, o total precipitado foi de $158 \mathrm{~mm}$ no Ciclo 1 e de $211 \mathrm{~mm}$ no Ciclo 2. Destaca-se ainda que houve coincidência de ocorrência de chuvas com período de maturação ou colheita das videiras, condições estas necessárias para a avaliação da resistência à rachadura de bagas das variedades de uvas de mesa.
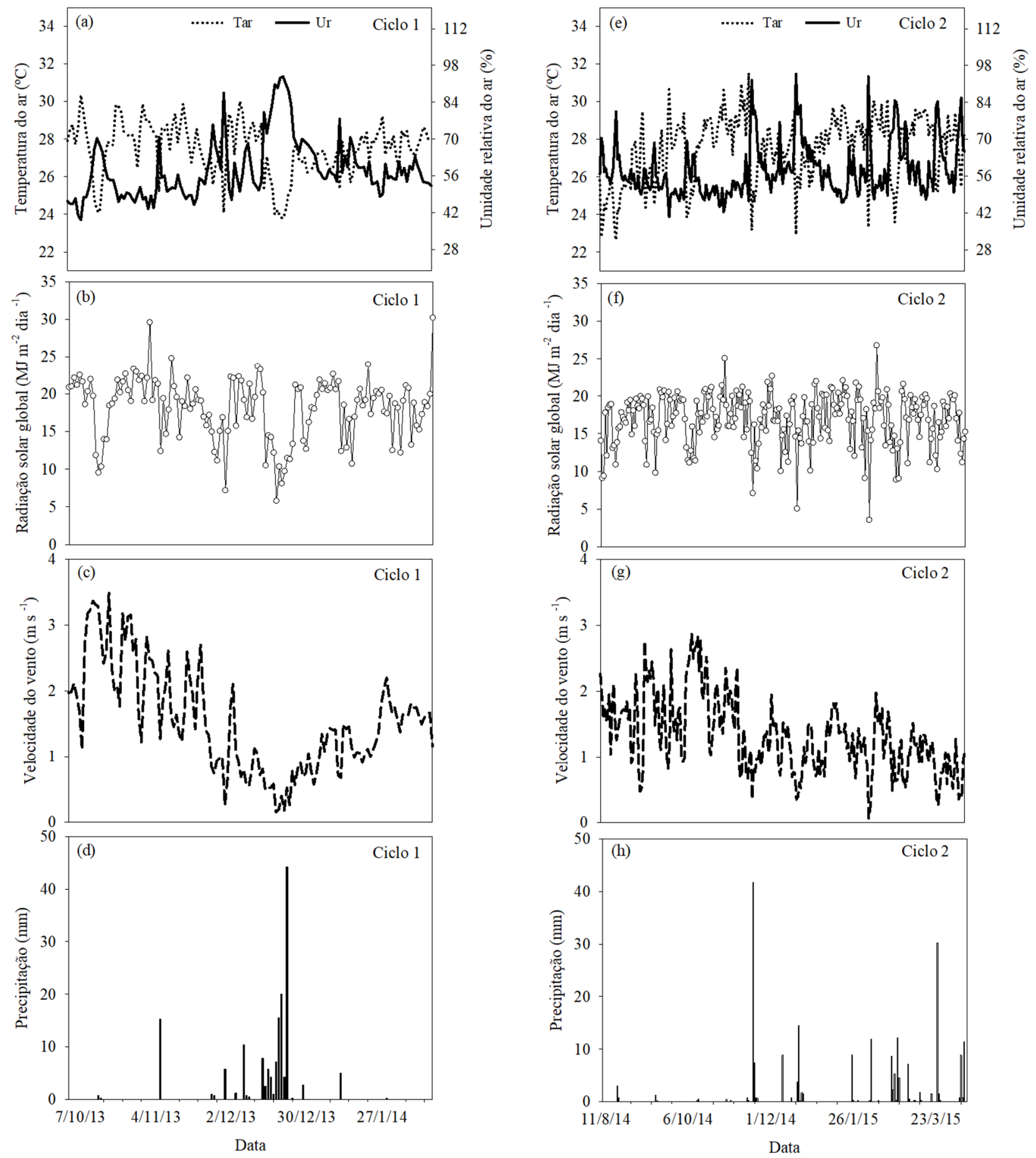

Figura 1. Variáveis meteorológicas durante o período de execução do experimento (Ciclo 1 e Ciclo 2) de uva de mesa sem sementes em Petrolina-PE: (a, e) temperatura do ar e umidade relativa do ar; $(b, f)$ radiação solar global; $(c, g)$ velocidade do vento; $(\mathrm{d}, \mathrm{h})$ precipitação.

A duração do ciclo fenológico de cada variedade de uva estudada nas diferentes datas de poda para o primeiro (Ciclo 1) e o segundo (Ciclo 2) ciclos é apresentada na Tabela 1 . Percebe-se que a duração do ciclo fenológico foi variável com as cultivares e com as datas de poda. A maior duração do período da poda à colheita ocorreu nas cultivares Adona e Arizul, com valores médios, respectivamente, de 121 e 115 dias, para o Ciclo 1 , e de 136 e 119 dias, para o Ciclo 2. As 
cultivares que apresentaram menor duração do ciclo da poda à colheita foram 'BRS Clara', com 100 dias, 'BRS Maria Bonita', com 100 e 108 dias, e 'Thompson Seedless', com 106 e 107 dias, para os Ciclos 1 e 2, respectivamente.

Tabela 1. Duração do ciclo fenológico de variedades de uva de mesa sem sementes produzida em diferentes datas de poda (D) em dois ciclos de produção, no Campo Experimental de Bebedouro, Petrolina-PE, em 2013 e 2014.

\begin{tabular}{|c|c|c|c|c|c|c|c|c|c|c|}
\hline \multirow{2}{*}{ Variedades } & \multicolumn{5}{|c|}{ Ciclo 1 - 2013} & \multicolumn{5}{|c|}{ Ciclo 2 - 2014} \\
\hline & D1 & D2 & D3 & D4 & Média & D1 & D2 & D3 & D4 & Média \\
\hline Adona & 122 & 120 & 119 & 121 & 121 & 120 & 135 & 129 & 158 & 136 \\
\hline BRS Clara & 100 & 100 & 100 & 99 & 100 & 105 & 95 & 100 & 101 & 100 \\
\hline BRS Maria Bonita & 100 & 100 & 100 & 99 & 100 & 107 & 113 & 101 & 109 & 108 \\
\hline Arizul & 113 & 108 & 119 & 121 & 115 & 120 & 120 & 121 & 113 & 119 \\
\hline Thompson & 105 & 108 & 106 & 105 & 106 & 105 & 109 & 106 & 109 & 107 \\
\hline
\end{tabular}

Considerando a duração do ciclo fenológico, foi determinado o acúmulo térmico ou o somatório de GD (Tabela 2). A variedade Adona mostrou o maior ciclo em dias e, consequentemente, acumulou maior quantidade de GD no Ciclo 1 e Ciclo 2, totalizando 2.117 e
2.405 GD da poda à colheita, respectivamente. A exigência térmica em GD para BRS Clara, BRS Maria Bonita, Thompson Seedless e Arizul foram de 1.764 e $1.769 ; 1.764$ e $1.903 ; 1.869$ e 1.902 ; 2.033 e 2.095 nos Ciclos 1 e 2 , respectivamente.

Tabela 2. Graus-dias acumulados para variedades de uva de mesa sem sementes produzida em diferentes datas de poda (D) em dois ciclos de produção, no Campo Experimental de Bebedouro, Petrolina-PE, em 2013 e 2014.

\begin{tabular}{|c|c|c|c|c|c|c|c|c|c|c|}
\hline \multirow{2}{*}{ Variedades } & \multicolumn{5}{|c|}{ Ciclo 1 - 2013} & \multicolumn{5}{|c|}{ Ciclo 2 - 2014} \\
\hline & D1 & D2 & D3 & D4 & Média & D1 & D2 & D3 & D4 & Média \\
\hline Adona & 2.130 & 2.110 & 2.093 & 2.135 & 2.117 & 2.068 & 2.386 & 2.321 & 2.844 & 2.405 \\
\hline BRS Clara & 1.779 & 1.775 & 1.761 & 1.741 & 1.764 & 1.809 & 1.692 & 1.789 & 1.825 & 1.779 \\
\hline BRS Maria Bonita & 1.779 & 1.775 & 1.761 & 1.741 & 1.764 & 1.841 & 1.994 & 1.807 & 1.970 & 1.903 \\
\hline Arizul & 1.995 & 1.909 & 2.093 & 2.135 & 2.033 & 2.068 & 2.111 & 2.172 & 2.029 & 2.095 \\
\hline Thompson & 1.857 & 1.909 & 1.860 & 1.850 & 1.869 & 1.809 & 1.928 & 1.903 & 1.970 & 1.902 \\
\hline
\end{tabular}

A Tabela 3 mostra os totais de chuva ocorridos nos últimos trinta dias dos dois ciclos de produção, para cada variedade, de acordo com as datas de poda. No Ciclo 1, o total de chuva ocorrido nos últimos 30 dias do período de produção das variedades BRS Clara e BRS Maria Bonita, correspondente à data D1, foi inferior a 30 $\mathrm{mm}$, enquanto para as outras variedades, o volume pluviométrico para esse mesmo período foi superior a $49 \mathrm{~mm}$, com destaque para a ocorrência de $127,5 \mathrm{~mm}$ na fase final do amadurecimento da uva 'Adona' e de 131,82 mm para 'Arizul'. Por outro lado, na data D2, as variedades BRS Clara e BRS Maria Bonita foram submetidas a 131,82 $\mathrm{mm}$ de chuva nos últimos 30 dias, ainda com lâminas superiores a $115 \mathrm{~mm}$ na D3. Tanto na D2 quanto na D3, a variedade Thompson Seedless finalizou seu ciclo com precipitação da ordem de $127 \mathrm{~mm}$ e $99 \mathrm{~mm}$, respectivamente. Em função da ocorrência de veranicos, que são períodos sem chuva dentro da estação pluviométrica, o ciclo de produção correspondente a quarta data (D4) se desenvolveu sem a ocorrência de chuvas superiores a $8,0 \mathrm{~mm}$ para todas as cultivares.

Tabela 3. Total de precipitação nos últimos 30 dias do ciclo de produção das variedades de uvas de mesa com diferentes datas de poda (D) em dois ciclos de produção, no Campo Experimental de Bebedouro, Petrolina-PE, em 2013 e 2014.

\begin{tabular}{|c|c|c|c|c|c|c|c|c|}
\hline \multirow{2}{*}{ Variedades } & \multicolumn{4}{|c|}{ Ciclo 1 - 2013 } & \multicolumn{4}{|c|}{ Ciclo 2 - 2014} \\
\hline & D1 & D2 & D3 & D4 & D1 & D2 & D3 & D4 \\
\hline Adona & 127,50 & 99,32 & 5,33 & 0,25 & 51,57 & 21,85 & 21,85 & 55,38 \\
\hline BRS Clara & 28,44 & 131,82 & 115,82 & 7,87 & 52,33 & 51,57 & 21,85 & 21,85 \\
\hline BRS Maria Bonita & 28,44 & 131,82 & 115,82 & 7,87 & 52,33 & 31,50 & 18,04 & 38,11 \\
\hline Arizul & 131,82 & 127,50 & 5,33 & 0,25 & 51,57 & 31,50 & 21,59 & 45,98 \\
\hline Thompson & 49,27 & 127,50 & 99,32 & 5,33 & 52,33 & 29,97 & 0,00 & 38,11 \\
\hline
\end{tabular}


Por sua vez, menores lâminas de chuva foram observadas no período final do Ciclo 2, quando se observou que o maior total precipitado nos últimos 30 dias, para todas as variedades, ocorreu nas videiras podadas na D1, com aproximadamente $52,33 \mathrm{~mm}$. As uvas podadas na D4 receberam diferentes volumes de chuva nos seus últimos trinta dias de ciclo produtivo, sendo que 'BRS Clara', 'Arizul' e 'Adona' foram submetidas a chuvas que totalizaram entre $21,85 \mathrm{e}$ $55,38 \mathrm{~mm}$, enquanto 'Thompson Seedless' e 'BRS Maria Bonita' receberam 38,11 mm.

Pode-se observar nas Tabelas 4 e 5 que o maior percentual de bagas rachadas e bagas podres foi obtido na variedade Thompson Seedless, nos dois ciclos, diferindo significativamente das demais variedades, indicando maior susceptibilidade à rachadura e podridão de bagas, seguida das variedades Arizul e BRS Maria Bonita. As variedades Adona e BRS Clara apresentaram menores percentuais de bagas rachadas e bagas podres (Tabela 4).

A produção média por planta para as variedades Adona, BRS Maria Bonita, BRS Clara,
Arizul e Thompson Seedless foram apresentadas na Tabela 5. As diferenças observadas podem ser atribuídas às características genéticas inerentes à cada variedade e que se correlacionam positivamente com a produção das videiras. Neste ciclo, maior produção por planta foi observada nas variedades Adona e BRS Maria Bonita comparadas à 'Thompson Seedless'.

No Ciclo 2 foi observado um incremento da ordem de $100 \%$ na produção por planta em relação ao ciclo anterior, com destaque para a variedade BRS Clara que diferiu significativamente de 'Thompson Seedless' e 'Arizul' (Tabela 5). Neste ciclo, os valores de produção obtidos corresponderam a produtividades estimadas em 34 t.ha $^{-1}$ na variedade BRS Clara, 29,2 t.ha' $a^{-1} \mathrm{em}$ 'Adona', 25 t.ha ${ }^{-1}$ em 'BRS Maria Bonita', 16, 7 t ha $^{-1} \mathrm{em}$ 'Thompson Seedless' e 15,5 t.ha ${ }^{-1}$ em 'Arizul'. Deste modo, pode-se constatar um aumento de produtividade de 50,8\% na 'BRS Clara' em relação à variedade comercial "Thompson Seedless".

Tabela 4. Percentagens de bagas rachadas e bagas podres de variedades de uva de mesa sem sementes em diferentes datas de poda (D) em dois ciclos de produção, no Campo Experimental de Bebedouro, PetrolinaPE, em 2013 e 2014.

\begin{tabular}{|c|c|c|c|c|c|c|c|c|}
\hline \multirow{3}{*}{ Variedades } & \multicolumn{4}{|c|}{ Bagas rachadas (\%) ${ }^{1}$} & \multicolumn{4}{|c|}{ Bagas podres (\%) ${ }^{1}$} \\
\hline & \multicolumn{8}{|c|}{ Ciclo 1 - 2013 } \\
\hline & D1 & D2 & D3 & D4 & D1 & D2 & D3 & D4 \\
\hline Adona & $0,15 \mathrm{~b}$ & $2,61 \mathrm{ab}$ & $0,32 \mathrm{ab}$ & $1,44^{\mathrm{ns}}$ & $2,51 \mathrm{ab}$ & $0,61 \mathrm{~b}$ & $0,35 \mathrm{~b}$ & $3,71^{\mathrm{ns}}$ \\
\hline BRS Clara & $1,12 \mathrm{ab}$ & $1,58 \mathrm{~b}$ & $0,00 \mathrm{~b}$ & $0,06^{\mathrm{ns}}$ & $0,00 \mathrm{~b}$ & $4,06 \mathrm{~b}$ & $18,40 \mathrm{ab}$ & $15,59^{\mathrm{ns}}$ \\
\hline BRS Maria Bonita & $0,49 \mathrm{~b}$ & $32,14 \mathrm{ab}$ & $0,88 \mathrm{ab}$ & $0,08^{\mathrm{ns}}$ & $9,04 \mathrm{ab}$ & $27,67 \mathrm{ab}$ & $28,53 \mathrm{ab}$ & $10,48^{\text {ns }}$ \\
\hline Arizul & $7,38 \mathrm{ab}$ & $0,80 \mathrm{~b}$ & $22,77 \mathrm{a}$ & $3,65^{\mathrm{ns}}$ & $59,94 \mathrm{a}$ & $43,06 \mathrm{ab}$ & $21,03 \mathrm{ab}$ & $22,95^{\mathrm{ns}}$ \\
\hline Thompson & $47,08 \mathrm{a}$ & $100,00 \mathrm{a}$ & $13,43 \mathrm{ab}$ & $2,51^{\mathrm{ns}}$ & $34,40 \mathrm{a}$ & $100,00 \mathrm{a}$ & $57,65 \mathrm{a}$ & $11,38^{\mathrm{ns}}$ \\
\hline Média & 11,25 & 27,43 & 7,48 & 1,55 & 21,18 & 35,08 & 25,19 & 12,82 \\
\hline $\mathrm{CV}$ & 1,16 & 0,45 & 0,95 & 1,08 & 0,44 & 0,45 & 0,41 & 0,70 \\
\hline \multirow[t]{2}{*}{$\mathrm{p}$} & 0,005 & 0,003 & 0,004 & 0,006 & 0,002 & 0,001 & 0,004 & 0,078 \\
\hline & \multicolumn{8}{|c|}{ Ciclo 2 - 2014} \\
\hline Adona & $0,97 \mathrm{~b}$ & $1,44 a b$ & $0,19 \mathrm{~b}$ & $0,33^{\mathrm{ns}}$ & $0,86 \mathrm{ab}$ & $0,63^{\mathrm{ns}}$ & $2,41 \mathrm{~b}$ & $26,24 \mathrm{ab}$ \\
\hline BRS Clara & $2,64 \mathrm{ab}$ & $0,56 \mathrm{~b}$ & $1,60 a b$ & $0,57^{\mathrm{ns}}$ & $0,47 \mathrm{~b}$ & $1,31^{\mathrm{ns}}$ & $24,21 \mathrm{ab}$ & $8,71 \mathrm{ab}$ \\
\hline BRS Maria Bonita & $32,99 \mathrm{ab}$ & $6,92 a b$ & $1,60 a b$ & $1,42^{\mathrm{ns}}$ & $8,46 \mathrm{a}$ & $8,78^{\mathrm{ns}}$ & $33,69 \mathrm{ab}$ & $30,71 \mathrm{a}$ \\
\hline Arizul & $1,33 \mathrm{~b}$ & $6,10 a b$ & 7,66 a & $1,47^{\mathrm{ns}}$ & $4,82 a b$ & $9,50^{\mathrm{ns}}$ & $9,73 \mathrm{ab}$ & $1,91 \mathrm{~b}$ \\
\hline Thompson & $75,59 \mathrm{a}$ & $63,14 \mathrm{a}$ & $2,75 a b$ & $4,39^{\mathrm{ns}}$ & $1,12 \mathrm{ab}$ & $5,30^{\mathrm{ns}}$ & $57,64 \mathrm{a}$ & $40,60 \mathrm{a}$ \\
\hline Média & 22,71 & 15,63 & 2,76 & 1,64 & 3,15 & 5,10 & 25,54 & 21,63 \\
\hline $\mathrm{CV}$ & 0,56 & 0,67 & 0,51 & 0,83 & 0,64 & 0,73 & 0,55 & 0,52 \\
\hline $\mathrm{p}$ & 0,005 & 0,007 & 0,009 & 0,061 & 0,005 & 0,024 & 0,004 & 0,012 \\
\hline
\end{tabular}

${ }^{1}$ Dados não seguiram distribuição normal, aplicando-se a estatística não paramétrica pelo teste de KruskalWallis; Médias seguidas pela mesma letra não diferem entre si pelo teste de Dunn $(\mathrm{p}<0,05)$; ns = não significativo.

O número de cachos por planta foi maior na variedade 'Adona', diferindo, significativamente, de todas as demais variedades no Ciclo 1, e de 'BRS Maria Bonita', 'Arizul' e
'Thompson Seedless', no Ciclo 2. A variedade BRS Maria Bonita destacou-se pela maior massa do cacho em ambos os ciclos de produção 
avaliados, mas que não diferiu de 'Adona' no Ciclo 1 e de 'BRS Maria Bonita' no Ciclo 2.

A variedade BRS Clara apresentou maior teor de sólidos solúveis em ambos os ciclos de produção, com diferenças significativas para 'BRS Maria Bonita' no Ciclo 1 e 'BRS Maria Bonita' e 'Thompson Seedless' no Ciclo 2. No Ciclo 1 todas as variedades caracterizaram-se por apresentar teor de sólidos solúveis acima do valor mínimo exigido, entretanto, no Ciclo 2, as variedades 'BRS Maria Bonita' e 'Thompson Seedless' não atingiram o valor aceitável para consumo da uva in natura. No que concerne à acidez titulável, observou-se maior valor médio de 0,72 e 0,60 na variedade BRS Clara e de 0,64 e 0,87 na variedade Adona, respectivamente, nos Ciclos 1 e 2 (Tabela 5).

Tabela 5. Características agronômicas de variedades de uva de mesa sem sementes produzidas durante dois ciclos de produção, no Campo Experimental de Bebedouro, Petrolina-PE, em 2013 e 2014.

\begin{tabular}{|c|c|c|c|c|c|}
\hline \multirow{3}{*}{ Variedades } & Producãã ${ }^{1}$ & $\mathbf{N}^{\mathbf{o}} \mathbf{d e}^{2}$ & Massa do ${ }^{2}$ & SS1 & $\mathbf{A T}^{2}$ \\
\hline & $\left(K_{g}\right.$ planta $\left.^{-1}\right)$ & cachos & Cacho (g) & Brix (\%) & \\
\hline & \multicolumn{5}{|c|}{ Ciclo 1 - 2013} \\
\hline Adona & $9,01 \mathrm{a}$ & $50,92 \mathrm{a}$ & $215,83 \mathrm{ab}$ & $18,98 \mathrm{ab}$ & $0,64 a b$ \\
\hline BRS Clara & $3,67 \mathrm{ab}$ & $23,58 \mathrm{c}$ & $149,24 \mathrm{bc}$ & $19,93 \mathrm{a}$ & $0,72 \mathrm{a}$ \\
\hline BRS Maria Bonita & $8,24 \mathrm{a}$ & $37,67 \mathrm{~b}$ & $274,13 \mathrm{a}$ & $14,76 \mathrm{~b}$ & $0,59 \mathrm{~b}$ \\
\hline Arizul & $2,95 \mathrm{ab}$ & $25,42 b c$ & $92,09 \mathrm{c}$ & $17,63 a b$ & $0,68 \mathrm{a}$ \\
\hline Thompson & $1,36 \mathrm{~b}$ & $10,00 \mathrm{~d}$ & $155,10 \mathrm{bc}$ & $19,80 \mathrm{a}$ & $0,67 \mathrm{ab}$ \\
\hline Média & 5,05 & 29,52 & 177,28 & 18,22 & 0,66 \\
\hline $\mathrm{CV}$ & 0,22 & 0,20 & 0,16 & 0,03 & 0,04 \\
\hline \multirow[t]{2}{*}{$\mathrm{p}$} & 0,003 & 0,000 & 0,000 & 0,005 & 0,002 \\
\hline & \multicolumn{5}{|c|}{ Ciclo 2 - 2014} \\
\hline Adona & $17,52 \mathrm{ab}$ & $98,83 \mathrm{a}$ & $236,77 \mathrm{~b}$ & $16,43 \mathrm{~b}$ & $0,87 \mathrm{a}$ \\
\hline BRS Clara & $20,63 \mathrm{a}$ & $93,17 \mathrm{a}$ & $304,28 \mathrm{~b}$ & $19,48 \mathrm{a}$ & $0,60 a b$ \\
\hline BRS Maria Bonita & $15,19 \mathrm{ab}$ & $41,08 \mathrm{bc}$ & $470,99 \mathrm{a}$ & $13,25 \mathrm{c}$ & $0,64 a b$ \\
\hline Arizul & $9,31 \mathrm{~b}$ & $52,25 \mathrm{~b}$ & $321,43 a b$ & $16,00 \mathrm{~b}$ & $0,55 \mathrm{~b}$ \\
\hline Thompson & $10,03 \mathrm{~b}$ & $17,00 \mathrm{c}$ & $279,76 \mathrm{~b}$ & $13,93 \mathrm{c}$ & $0,62 \mathrm{ab}$ \\
\hline Média & 14,53 & 60,47 & 322,65 & 15,82 & 0,66 \\
\hline $\mathrm{CV}$ & 0,27 & 0,24 & 0,17 & 0,04 & 0,08 \\
\hline $\mathrm{p}$ & 0,018 & 0,000 & 0,004 & 0,000 & 0,011 \\
\hline
\end{tabular}

${ }^{1}$ Dados não seguiram distribuição normal, aplicando-se a estatística não paramétrica pelo teste de KruskalWallis; Médias seguidas pela mesma letra não diferem entre si pelo teste de Dunn $(\mathrm{p}<0,05)$; ${ }^{2}$ Dados seguiram distribuição normal, aplicando-se a estatística ANOVA; Médias seguidas pela mesma letra não diferem entre si pelo teste de Tukey $(\mathrm{p}<0,05)$.

\section{Discussão}

Considerando os resultados encontrados, pode-se constatar que em ambos os ciclos, cada variedade se desenvolveu sob diferentes condições climáticas, particularmente no período de maturação das bagas. Segundo Souza (1996), o clima é o principal fator que exerce influência sobre o desenvolvimento da videira, entretanto, considerando-se as mesmas condições climáticas, variedades diferentes poderão apresentar comportamentos fenológicos distintos, podendose concluir que a fenologia é uma manifestação evidente da interação entre genótipos e ambiente.

Quando se estabeleceu uma comparação entre os dados do ciclo fenológicos obtidos no presente estudo e os reportados na literatura, constatou-se que os mesmos foram semelhantes aos resultados observados por Leão et al. (2013), que analisando o ciclo fenológico de cultivares de uva de mesa durante o segundo semestre entre os anos de 2002 e 2011 nas condições climáticas do Vale do Submédio São Francisco, observaram um maior percentual de cultivares precoces no grupo de uvas sem sementes, onde as cultivares Adona, Arizul, Thompson Seedless e BRS Clara, apresentaram duração do ciclo com 131 dias (tardia), 117 dias (mediana), 101 dias (mediana) e 99 dias (precoce), respectivamente.

No que concerne, o somatório de grausdias, constatou-se que a variedade Adona destacou-se com maior duração do ciclo, resultando, acúmulo térmico maior em ambos os ciclos. Segundo Sentelhas (1998), a determinação da necessidade térmica, em graus-dia, é valiosa para a viticultura, pois permite estimar a duração do ciclo de produção da videira, favorecendo um melhor planejamento das atividades agrícolas no parreiral, como melhor época para realização da 
poda e da colheita. Para uva de mesa cultivada sob condições tropicais, principalmente variedades com elevados índices de rachadura de bagas devido à precipitação na colheita, é importante se observar o calendário da região, com vistas a realizar a poda de acordo com o ciclo fenológico da cultivar, de modo que a colheita seja evitada quando há maior probabilidade de ocorrer chuva, segundo as características climáticas predominantes na área de cultivo. Dessa forma, constatou-se, que os diferentes volumes pluviométricos que ocorreram nas videiras nos dois ciclos de produção avaliados, nas diferentes datas de poda, proporcionaram índices de rachadura e podridões diferenciados, demonstrando ser o total pluviométrico da fase final de maturação o período mais crítico para sua ocorrência. Assim, os resultados mostraram que tanto o percentual de rachamento quanto o de podridão apontaram para as variedades BRS Clara e Adona como as mais tolerantes, podendo ser indicadas para produção cuja colheita ocorra no período chuvoso, e a variedade Thompson Seedless como a mais suscetível.

Com relação à produtividade, de maneira geral, verificou-se maior produção no Ciclo $2 \mathrm{em}$ relação ao Ciclo 1, com destaque para a variedade BRS Clara enxertada no porta-enxerto 'Paulsen 1103', que obteve produção por planta e produtividade estimada em torno de 20,63 kg.planta ${ }^{-1}$ e 34 t.ha $^{-1}$, respectivamente, esses valores foram superiores àqueles observados por Colombo et al. (2011), que obteve para a mesma variedade na safra de 2008 sobre o porta-enxerto IAC 766, produtividade de 17,3 kg.planta ${ }^{-1}$ e 14,4 t.ha ${ }^{-1}$. Leão (2011), analisando a produtividade e qualidade de uvas de mesa sem sementes 'Sugraone' produzidas sobre diferentes portaenxertos no Submédio do Vale São Francisco, observou maior produtividade estimada de 12 t.ha ${ }^{-}$ 1 para o porta-enxerto 'Paulsen 1103' em quatro ciclos. Feldberg et al. (2007), em MocambinhoMG, constataram que, na média das cinco safras avaliadas para as videiras 'Crimson Seedless', o porta-enxerto 'Paulsen 1103' induziu ao aumento de $50,6 \%$ no número de cachos. Portanto, Yamamoto et al. (2012) ressalta que a produção das videiras é influenciada por vários fatores, como: características da variedade e do portaenxerto, sistemas de condução, tipos de poda, fertilidade do solo, práticas culturais utilizadas em cada região e condições edafoclimáticas.

Quanto ao teor de sólidos solúveis, observou-se o destaque das variedades BRS Clara e Adona nos diferentes ciclos de produção, apresentando teor de sólidos solúveis acima do valor mínimo exigido para a comercialização de uvas finas de mesa, que é de $14{ }^{\circ}$ Brix (BRASIL, 2002). Segundo Souza (2010), os cachos da cultivar BRS Clara podem atingir em torno de 19,0 ${ }^{\circ}$ Brix durante a colheita, valor este observado no presente estudo, no qual foi maior do que os determinados por Mascarenhas et al. (2013), que obteve teor de sólidos solúveis entre $15,8^{\circ}$ Brix e $16,5^{\circ}$ Brix para as variedades de uvas finas de mesa 'Benikata', 'Itália', 'Brasil' e 'Red Globe' produzidas no Vale do São Francisco. Em relação à acidez titulável em uvas de mesa, segundo Lima \& Choudhury (2007), deve ser de, no máximo, $1,50 \%$ de ácido tartárico. Desta forma, todas as uvas de mesa deste estudo apresentaram valores satisfatórios para o consumo.

\section{Conclusão}

As variedades BRS Clara e Adona apresentaram tolerância a rachadura e podridão da baga, aliada a boa produtividade, número de cachos, teor de sólidos solúveis e acidez total adequados para o consumo. Estas variedades podem ser indicadas para o cultivo de uvas de mesa de duas safras, com colheitas em qualquer época do ano, com menores riscos de perdas para os produtores do Submédio do Vale São Francisco.

\section{Agradecimentos}

À Fundação de Amparo à Ciência e Tecnologia de Pernambuco-FACEPE pela Bolsa BFT da primeira autora (Processo BFT-01571.07/15) e à Empresa Brasileira de Pesquisa Agropecuária (Embrapa) pela infraestrutura disponibilizada e auxílio financeiro.

\section{Referências}

AGRIANUAL. 2016. Anuário da Agricultura Brasileira. Instituto AgraFNP. 449p.

AOAC. 1995. Association of Official Analytical Chemistry. Official methods of analysis. 16. ed. Arlington. 1141p.

BALBONTÍN, C.; AYALA, H.; BASTÍAS, R.M.; TAPIA, G.; ELLENA, M.; TORRES, C.; YURI, J. A.; QUEROGARCÍA, J.; RÍOS, J. C.; SILVA, H. 2013. Cracking in sweet cherries: A comprehensive review from a physiological, molecular, and genomic perspective. Chil. J. Agric. Res., v. 73, n. 1, p. 66-72.

BRASIL. 2002. Ministério da Agricultura, Pecuária e Abastecimento. Instrução normativa $\mathrm{n}^{\mathrm{o}} .1$, de 1 de fevereiro de 2002. Aprova o Regulamento Técnico de Identidade e de Qualidade para a 108 Classificação da Uva Fina 
de Mesa. Diário Oficial da República Federativa do Brasil, Brasília, DF.

COLOMBO, L. A.; ASSIS, A. M.; SATO, A. J.; TESSMANN, D. J.; GENTA, W.; ROBERTO, S. R. 2011. Produção fora de época da videira 'BRS Clara' sob cultivo protegido. Ciência Rural, v. 41, n. 2, p. 212-218.

EMBRAPA SEMIÁRIDO. Médias Anuais da Estação Agrometeorológica de Bebedouro. Disponível em: http://www.cpatsa.embrapa.br:8080/servicos/dado smet/ceb-anual.html. Acesso em: 11 abril, 2017.

FAVA, J.; HODARA, K.; NIETO, A.; GUERRERO, S.; ALZAMORA, S. M.; CASTRO, M. A. 2011. Structure (micro, ultra, nano), color and mechanical properties of Vitis labrusca L. (grape berry) fruits treated by hydrogen peroxide, UV-C irradiation and ultrasound. Food Research International, v. 44, n. 9, p. 2938-2948.

FELDBERG, N. P.; REGINA, M. A.; DIAS, M. S. C. 2007. Desempenho agronômico das videiras 'Crimson Seedless' e 'Superior Seedless' no Norte de Minas Gerais. Pesq. Agropec. Bras., v. 42 , n. 6, p. 777-783.

LANG, A.; DÜRING, H. 1990. Grape berry splitting and some mechanical properties of the skin. Vitis, v. 29, n. 1, p. 61-70.

LEÃO, P. C. S. 2002. Comportamento de Cultivares de Uva sem sementes no Submédio São Francisco. Rev. Bras. Frutic., v. 24, n. 3, p. 734-737.

LEÃO, P. C. S. et al. 2013. Caracterização Fenológica de Cultivares de Uvas de Mesa do Banco de Germoplasma da Embrapa Semiárido. Boletim de Pesquisa e Desenvolvimento. Embrapa Semiárido, ISSN: 1808-9968. 21p.

LEÃO, P. C. S.; BRANDÃO, E. O.; GONÇALVES, N. P. S. 2011. Produção e qualidade de uvas de mesa 'Sugraone' sobre diferentes porta-enxertos no Submédio do Vale do São Francisco. Cienc. Rural, v. 41, n. 9, p. 15261531.

LIMA, M. A. C.; CHOUDHURY, M. M. 2007. Características dos cachos de uva. In: LIMA, M. A. C. (Ed.). Uva de mesa: pós-colheita. 2.ed. Brasília: Embrapa Informação Tecnológica; Petrolina: Embrapa Semiárido. pp. 21-30.
MELLO, L. M. R. 2009. Atuação do Brasil no mercado vitivinícola mundial: panorama 2009. Bento Gonçalves: EMBRAPA/CNPUV.

MOURA, M. S. B.; SOARES, J. M.; GURGEL, M. T.; LEITÃO, M. M. V. B. R.; OLIVEIRA, G. M. 2006. Evapotranspiração e coeficiente de cultivo da videira em ambiente protegido. In: Anais Congresso Brasileiro de meteorologia, Florianópolis-SC, Brasil.

MASCARENHAS, R. J.; GUERRA， N. B.; AQUINO, J. S.; LEAO, P. C. S. 2013. Qualidade sensorial e físico-química de uvas finas de mesa cultivadas no Submédio São Francisco. Rev. Bras. Frutic., v. 35, n. 2, p. 546-554.

OMETTO, J. C. 1981. Bioclimatologia vegetal. São Paulo: Agronômica Ceres. 440p.

SENTELHAS, P. C. 1998. Aspectos climáticos para viticultura tropical. Informe Agropecuário, v. 19, n. 194, p. 9-14.

SOARES, J. M.; LEAO, P. C. S. 2009. (Ed.). A vitivinicultura no Semiárido brasileiro. Embrapa Informação Tecnológica: Brasília, DF; Embrapa Semi-Árido: Petrolina, PE. 756p.

SOUZA, J. S. I. 1996. Uvas para o Brasil. 2. ed. Piracicaba: FEALQ. 791p.

SOUZA, R. T. 2010. Resposta da cultivar BRS Clara ao manejo da copa e do cacho. Bento Gonçalves: Embrapa Uva e Vinho. 3p.

TEIXEIRA, A. H. C. 2004. Cultivo da videira clima. Disponível em: http://www.cpatsa.embrapa.br:8080/sistema_prod ucao/spvideira/clima.htm. Acesso em: 19 abril, 2017.

YAMAMOTO, T.; SATOH, H. 1994. Relationship among berry cracking susceptibility, berry morphology and skin stress distribution in several grape cultivars. Journal of the Japanese Society for Horticultural Science, v. 63, n. 2, p. 247-256.

YAMAMOTO, L. Y.; ASSIS, A. M.; MORAIS, H.; SOUZA, F. S.; SCAPIN, C. R.; TESSMANN, D. J.; SOUZA, R. T.; ROBERTO, S. R. 2012. Produção e características físico-químicas dos cachos da videira 'BRS Clara' sob cobertura plástica e sombrite em safra fora de época. Rev. Bras. Frutic., v. 34, n. 1, p. 160-166. 